Article

\title{
Energy Management System Application for Sustainable Development in Wood Industry Enterprises
}

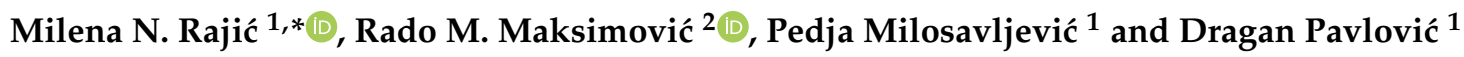 \\ 1 Department of Management in Mechanical Engineering, Faculty of Mechanical Engineering, \\ University of Niš, 18000 Niš, Serbia; pedja@masfak.ni.ac.rs (P.M.); dragan.pavlovic@masfak.ni.ac.rs (D.P.) \\ 2 Department of Industrial Engineering and Management, Faculty of Technical Sciences, \\ University of Novi Sad, 21000 Novi Sad, Serbia; rado@uns.ac.rs \\ * Correspondence: milena.rajic@masfak.ni.ac.rs; Tel.: +381-18638721009
}

Received: 16 November 2019; Accepted: 17 December 2019; Published: 20 December 2019

\begin{abstract}
This study analyzes the energy management approach as one of the driving factors for sustainable development, not only in enterprises, but also countries. Sustainability of an enterprise is defined as its tendency to meet the need of customers and stakeholders through creative and innovative business strategies as well as activities that have a positive influence on society and environment. In this study, sustainability is measured through the application of an energy management system, but in the wood industry, which has an increasingly significant impact on the economic development in one country. The aim of this research is to determine the current situation regarding the application of energy management practices in production and service systems. The ISO 50001 standard for energy management systems considers the energy performance achieved by an enterprise. The connections between critical factors and the level of application requirements for the energy management system were statistically analyzed in this research. It was found that in enterprises that have a certified system of quality and environmental management, a higher level of energy management system implementation is evident. The research results provide data on the scientific level for the national policy improvement, as well as a developed model based on the Plan Do Check Act (PDCA) cycle for energy management system application.
\end{abstract}

Keywords: energy management; ISO 50001; enterprises; sustainability; wood industry

\section{Introduction}

Sustainable development of enterprises implies a constant struggle between an innovative business approach and the preservation of resources. Researchers in this field emphasize different views of sustainable development [1,2]. The rational use of energy represents an increasing challenge for companies, with the aim of preserving the environment [3-7]. Material and energy flows, as well as their mutual interactions, have a major impact on the business model formation, whether they are flexible and applicable to different production and/or service activities and if they provide enough information to design a process with as much resource savings as possible and with a less negative impact on the environment. Industrial systems, primarily production systems, are the largest energy consumers, especially in the wood industry.

According to [8], wood processing and wood product manufacturing, excluding furniture manufacturing, increased by $1.1 \%$ in 2018 compared with the previous year, while furniture manufacturing itself increased by $6.3 \%$. In 2018, the international trade of forest products increased by $18.3 \%$ while furniture exports increased by $12 \%$ in Serbia. The wood industry in Serbia remains 
one of the few economic activities that not only has a constant surplus in international trade, but has also been increasing every year. It is especially important for this country as one of the developing countries with an unstable economy.

It is considered that the efficient use of wood products also includes material and energy flow not only in the economic sector, but also forestry, manufacturing, and construction, as well as waste management of the products. Manufacturing industries are considered to be the most analyzed systems for the development of these models [9-12], along with optimizing resources in the wood industry [13]. Leading to high production costs and limited material sources, significant progress has been made in achieving high system performance through innovative solutions for energy savings and the redesign of production processes [14-16]. The redesign of energy flows, especially in manufacturing, can significantly improve the overall life cycle environment performance of wood products [11].

The basic factors that determine the production processes are certainly the price of energy and the cost of energy flows. It is noted that over $80 \%$ of energy needs in the industry are compensated by using fossil fuels [17]. Cost reduction is considered as one of the critical elements in proper energy management, because energy savings reduce production costs and increase profits [18]. Also, energy efficiency represents one of the key elements of sustainable development $[19,20]$. Especially important is the data that estimates that the energy consumption will increase at the global level by $33.5 \%$ from 2010 to 2030 [17]. In 2000, the industrial sector used $32 \%$ of the final energy in the world, as indicated in the study on the potential energy savings in the petrochemical industry [20]. In the industrial sector, the energy use varies from $30 \%$ to $70 \%$ of the total energy according to [21]. According to [22,23], the energy efficiency of the industrial sector is certainly one of the most important priorities for monitoring and control.

The energy management system offers many benefits, such as optimizing energy consumption, reducing costs, improving the corporate image of the enterprise, reducing the negative impact on the environment. Therefore, organizations have developed more suitable approaches to energy management, with the aim of reducing energy losses [24-27]. An Energy Management System (EnMS) begins with an energy policy, defines energy goals and ways to achieve these goals, forms a system for monitoring energy performance, and implements procedures for a continuous improvement of energy performance [28]. The ISO 50001:2011 standard does not define specific performance criteria related to energy consumption and efficiency. Instead, it proposes a management model that contributes to the development and implementation of the energy policy in order to achieve the objectives and action plans, taking into account legal requirements and information resulting from the analysis and management energy consumption data. The standard describes the ultimate goal, but not the way in which it can be achieved, and it does not allow the organization to fully understand its position on the way to the ultimate goal.

This study presents the methodology based on the PDCA model from the ISO 50001 standard. The aim was to determine the current state of EnMS implementation and enterprise energy management awareness in the wood industry. The research was conducted by using a questionnaire within ISO 50001 requirements. The research results also include small and medium-sized enterprises (SMEs). Results of the questionnaire are evaluated according to the analytical framework that covers company characteristics and organizational conditions. This study represents the basis of scientific data for improving the national energy policy as well as planning activities within the implementation of the ISO 50001 standard in terms of sustainability. Moreover, the Serbian industry and stakeholders can utilize the data as a benchmarking tool for comparing their results with the relevant ones in that field, or with the industrial average. The presented data can also be used and implemented in other markets, countries, and sectors to benchmark their results. Identifying the difference between the full requirements application of the ISO 50001 (as a reference for EnMS requirements) and the level of real implementation, this paper gives an insight into how energy management is implemented in the Serbian wood industry. 
This paper is structured as follows: Section 1 defines the research context and reviews the recent relevant literature, Section 2 discusses the methodology of the research, while Section 3 analyzes the energy management implementation in Serbia's wood industry, as one of the developing sectors, grouped according to the PDCA cycle. Section 4 presents the discussion of the results, and finally the summary of the study results is presented in Section 5 .

\section{Methodology}

This research was conducted by using a questionnaire and data collected from interviews in enterprises that belong to the wood industry in Serbia. One-hundred and four enterprises participated in this research, including all sectors connected to the wood industry. The research sample used in this research includes different territories of the Republic of Serbia, showing diversity, and has the aiming to include different regions that are not industrially developed and urbanized. The main contribution was that small and mid-size enterprises were included in this research, making this a unique study in the wood industry in Serbia. What is important to emphasize is that the size of the enterprise, the level of development, as well as the present duration on the market, influence different approaches to the energy management system.

The analyzed research sample includes production and service enterprises in the wood industry that are operating in Serbia, both with foreign and domestic ownership. The enterprises had to fulfill certain criteria such as: To be registered in the Business Registers Agency in the Republic of Serbia as a company or an entrepreneur and to be an active enterprise (not in bankruptcy or restructuring). The distribution of enterprises by economic activity is: Cutting and wood processing $18.27 \%$; furniture production $16.35 \%$; production of pellets, cork, straw, and wicker $29.81 \%$; manufacture of construction materials $13.46 \%$; trade $22.12 \%$. It was of great importance that managers, quality managers and, where applicable, energy managers respond to the questionnaire.

Statistical methods were applied for data processing. The average, standard deviation, and minimal and maximal values were calculated for the analyzed parameters. In order to obtain more accurate data and analyze the current state, it was necessary to collect some basic information about the enterprises, their management, and business activities, as well as production and service processes. The Mann-Whitney U test and Kruskal-Wallis test were used for qualitative analysis, and the results are presented in this paper.

There were 104 enterprises from different territories of the Republic of Serbia. The territorial division was adopted according to [29], and the Republic of Serbia was divided into five regions. Due to the difficulties in collecting data from Kosovo and Metohija, this region was not included in the study. According to the territorial division of the enterprises surveyed, most of them came from the city of Belgrade and the Šumadija region, $(29.81 \%)$ and (28.85\%), respectively, being the regions with a strong industrial background in this sector, followed by South and East Serbia (25\%) and Vojvodina $(16.35 \%)$.

In the first part of the paper, it was noted that the wood industry, especially in the last two decades, has been based on small and medium sized enterprises, with regard to the profile of small companies that are more flexible to market demands. The majority of enterprises in this research are, in fact, micro enterprises (up to 10 employees) $74.04 \%$, followed by small enterprises (from 11 to 50 employees) $15.38 \%$ and medium-sized enterprises (from 51 to 250 employees) $6.73 \%$, and finally large enterprises (more than 251 employees) with only 3.85\%. The first part of the questionnaire was related to the profile of the enterprise, not only its size (number of employees), but also the plant surface area, manufacturing area, and accompanied facilities of the enterprise. The plant surface area of the enterprises in the research sample is in the range from $100 \mathrm{~m}^{2}$ to $55,000 \mathrm{~m}^{2}$, with the average value $3186.15 \mathrm{~m}^{2}$, while the standard deviation of $4237.05 \mathrm{~m}^{2}$ indicated that the enterprises had a large deviation of the area in the sample.

It is important to know whether the enterprises show any interest in and make efforts to apply current standards, and how many of them have a certified management system. The majority have implemented ISO 9001 (Quality Management System)—54.81\% enterprises, but also ISO 14001 
(Environmental Management System) - 30.77\%, and ISO OHSAS 18001 (Health and Safety Management System) $-28.85 \%$. The number of enterprises that have not implemented any management system is $47(45.19 \%)$, which is a crucial piece of data for further analysis. The majority $(37.5 \%)$ has been present on the market for more than 10 years, while $19.23 \%$ of the research sample has been present for only up to 3 years.

For the second part of the questionnaire, which represents the energy profile of enterprises, it was important to obtain the data about the age of equipment installed within the plant. Old and non-serviced equipment was considered to be energy-inefficient. The largest number of enterprises $(57.69 \%)$ indicated that the average age of the installed equipment was between 5 and 10 years, $27.88 \%$ own new equipment up to 5 years old, while $14.42 \%$ operate with equipment that is older than 10 years. In order to define the energy profile of an enterprise that depends on the complexity of production processes, a part of the questionnaire required data about the number of used energy sources, such as electricity, natural gas, oil, compressed air, overheated water vapour, solar energy, wind energy, geothermal energy. The majority $(88.46 \%)$ use only one or possibly two energy sources, while $11.54 \%$ of the enterprises use 3 or more different energy sources. The interviewed enterprises assessed how many significant energy consumers they had and what their average annual energy consumption was: $67.31 \%$ of enterprises indicated that they have fewer than 5 critical or significant consumers, $27.88 \%$ between 6 and 10 crucial consumers, and only $4.81 \%$ more than 11 , while $38.46 \%$ of the researched enterprises have the annual energy consumption between $200 \mathrm{TJ}$ and $2000 \mathrm{TJ} ; 35.58 \%$ less than 200 TJ; $25 \%$ between $2000 \mathrm{TJ}$ and 10,000 TJ, and only $0.96 \%$ more than 10,000 TJ. These data provide the basis for further energy audits and energy consumption monitoring, as well as control and monitoring of key energy consumers within the production plant. Furthermore, there was also a part concerning the number of people that are in charge and have any connection with energy management in the process of the analyzed enterprise, in order to assess the willingness of these enterprises to implement the energy management system. According to the results, $57.69 \%$ of the research sample have only one person in charge of energy management. On the other hand, $8.65 \%$ of the research sample have 3 persons dealing with this issue, $3.85 \%$ of the sample have 2 persons, while $29.81 \%$ do not have any employed person who can in any way monitor the energy consumption or propose energy savings.

\section{Results-Implementation of Energy Management System in Wood Industry}

The ISO 50001 standard provides support to enterprises in all sectors regarding a more efficient energy use, through the implementation and development of an energy management system (EnMS). This model of the EnMS is based on the PDCA (Plan-Do-Check-Act) model cycle. This model is used in this research, but also developed for SMEs that operate in Serbia. It now includes a model for systematic observation and measurement of the implementation level of energy management in an enterprise, and can be easily used for further research in other countries. It should be noted that if the enterprise does not have a certified energy management system, it does not necessarily mean that it does not apply it in certain parts or sectors of its business. The questionnaire that is used as well as the provided answers are given in the Supplementary Material.

\subsection{Energy Planning and Identifying the Energy Management Enterprise Basis-The PLAN Phase of EnMs}

The first phase of EnMS is energy planning or the PLAN phase, and the whole EnMS base is, in fact, defined in this phase. The researched enterprises do not have a systematic energy management approach in general, but it is necessary to emphasize that achieving energy savings by reducing energy consumption requires time and is one of the long-term goals, not only for the enterprise itself, but also for employees. Namely, the average application of the PLAN phase in this research is $32.56 \%$. It means that the enterprises do not show willingness for energy planning. The average response about the implementation of the systematic approach is $22.24 \%$. Therefore, it can be noticed that special efforts are needed to inform and raise awareness, educate, and train employees that have the 
responsibility and managerial authorization in the enterprise on what represents the requirements for the energy management system. Within the systematic approach, $32.12 \%$ of the enterprises have implemented a system through which they monitor, document, and maintain energy consumption in processes. This group certainly includes enterprises that have certified ISO 14001 and ISO 50001 as well. When it comes to the issue of the application area of the energy management system (whether it refers to the whole plant, part of the plant, one or more sectors, production line, etc.), $20.19 \%$ of the enterprises recognize which part of the plant is the most significant from the aspect of energy use. In most manufacturing enterprises, this is the area of the machine hall, which is mainly a major energy user, while in the production sector it can also refer to only one production line. The rules and procedures of an enterprise are in the form of a documented procedure according to the requirements of EnMS. Data analysis shows that only $12.98 \%$ of enterprises state that there is a document/procedure that somehow determines effective energy management (which may be an integral part of the rules of procedure, but it does not have to be). $23.56 \%$ of the research sample responded that they have an organizational system that includes a continuous improvement of the performance of the energy system, as well as energy efficiency. It implies that the existence of a system is not enough, but it is necessary to constantly monitor and control energy indicators that are directly related to the rational use of energy and efficiency of the system.

The system approach to energy management according to the ISO 50001 standard belongs to the systematization of the PLAN phase, which also includes the part referring to leadership, energy planning, requirements of standards and regulations related to energy, energy profile of the enterprise, as well as energy goals. The support of the enterprises' management is crucial for the implementation of any management system in almost all enterprises, regardless of size, activity, or type of business. Within the current ISO 9001 and ISO 14001 standards, there are leadership requirements, which indicate that the management should be an active participant in the implementation, functioning, and maintenance of the management system. The average implementation level regarding leadership in EnMS is $37.18 \%$. The results show that $34.13 \%$ of enterprises clearly define and determine responsibilities as well as competences in order to ensure effective energy management. Regarding the support of the management to promote the importance of energy savings and energy efficiency, $33.17 \%$ of the researched enterprises state that the management emphasizes and promotes the importance of energy efficiency and effective energy management at all levels. A significant share of enterprises $44.23 \%$ state that the management raises the awareness of energy efficiency among employees.

Energy planning or an energy consumption plan according to ISO 50001 contains regulations that are important for monitoring and eventual improvements in energy performance within an enterprise. The average level of the implementation of energy planning in enterprise activities is $31.73 \%$. Energy consumption planning is most often realized within the framework of defining environmental plans, which are the annual plans for the necessary amount of energy resources (natural gas, electricity, oil, etc.). The plan of energy consumption is a mandatory part of the reports made and submitted by individual enterprises to the Ministry of Mining and Energy of the Republic of Serbia. The collected data related to energy planning indicate not so positive results of the research. Namely, $29.33 \%$ of the surveyed enterprises include energy performance of the processes, plants, and business in general in long-term plans, while $38.94 \%$ of enterprises have a defined plan of energy use, energy savings, and system performance that is necessary to achieve in a defined period, and only $26.92 \%$ define their plan of activities related to the energy performance of the system.

In addition to legal requirements and regulations that are mandatory, enterprises may have different attitudes regarding legal requirements that do not have mandatory legal application, for example, standards such as ISO 50001. The average level of application of requirements of EnMS standards and regulations is $28.61 \%$. Regarding the analysis of the research results, $28.85 \%$ of the researched enterprises identified, applied, and had access to the appropriate requirements defined by legislation (regulations, rules) related to energy use, its consumption, and efficiency. Also, approximately the 
same number of enterprises, $28.37 \%$, ensured that these requirements were respected and monitored at a certain period.

As part of this phase, the enterprises also defined their energy profile. The energy profile was determined by the implementation of energy audit procedures. An energy audit can be defined according to [30] as a systematic control and analysis of energy use and energy consumption of the system or enterprise, with the aim of identifying energy flows and possibilities of improving energy efficiency. In [30], it is said that determining the energy profile includes identifying and defining all sources of energy that an enterprise uses, identifying and defining all energy consumers, amount of energy consumption, as well as the condition of equipment and machinery used by the enterprise. The energy profile is determined at the very beginning of EnMS and represents a direction for energy performance improvement. The researched enterprises with defined requirements for the energy profile comprised $35.51 \%$. The research data showed that $19.23 \%$ of enterprises carry out energy audits, which indicates the extent to which the energy performance of the system within the enterprise is controlled and monitored. This data indicates the insufficient willingness of the enterprises to include in their business processes the optional audits related to energy consumption, which is very discouraging, since $43.24 \%$ of the enterprises have implemented ISO 14001, which implies monitoring of energy consumption and determination of critical consumers. Only $19.71 \%$ of enterprises have clearly defined methodology and criteria for the development and implementation of energy audits, which means that there is a lack of clear methodology or procedure for audits. In order to develop and improve energy audits, it is necessary to analyze the energy use and/or consumption within the enterprise and to have detailed measurement and identification of current energy sources. At this stage, $38.94 \%$ of the surveyed enterprises are at that level and show willingness for it. Regarding the data on the current energy consumption, as well as the archives of old energy consumption data, the results are quite satisfactory. Namely, $67.79 \%$ of enterprises have records of energy consumption in the past, so that they can compare it with the current consumption; $66.83 \%$ of enterprises document energy consumption and energy costs for a certain period; but $25 \%$ of enterprises consider possibilities for energy savings and energy efficiency at regular meetings (monthly, quarterly). Also, one of the criteria for defining the enterprises' energy profile is to determine the current state of the existing building and production halls using standard methodologies, such as building certification and obtaining a building energy passport. The information on the existence of a building energy passport that an enterprise owns (administrative building, factory, production hall, etc.) is present in only $11.06 \%$ of the researched enterprises.

Defining the enterprises' energy goals can be associated with the future desired objective of the management, along with what effects they want to achieve and in what period. This can be achieved by applying organizational and/or technological measures to improve energy efficiency. The researched enterprises apply an average of $38.3 \%$ of requirements in terms of defining energy goals. In order to achieve certain enterprise goals, the management should also define an action plan for achieving certain general or specific energy goals. Regarding clearly defined goals and constraints related to energy consumption in an enterprise, $32.69 \%$ of the researched enterprises state that they have clearly defined goals and limitations related to energy consumption. When it comes to action plans that should result from the defined goals, $40.87 \%$ of enterprises define the action plans for achieving energy consumption targets, in which specific tasks, necessary recourses, deadlines, as well as responsibilities of employees regarding the fulfillment of those tasks are defined. The research data shows that $41.35 \%$ of enterprises actually implement previously defined action plans for energy savings, as well as monitor energy consumption. When defining energy goals in enterprises, the limiting factor is definitely the lack of financial resources for the reconstruction and installation of equipment, machines, and devices, in order to achieve better energy performance. Enterprises also state that there are no corresponding supporting funds from the state budget or any other available funds, in order to consider purchasing new equipment or planning reconstruction of the existing one. This certainly influences defining and predicting action plans, because without adequate financial means it is impossible to make important changes in the performance of production processes. 
Figure 1 shows the implementation of the PLAN phase in enterprises in Serbia. Full implementation of planning in energy management is present in only $1.92 \%$ of enterprises, with $12.5 \%$ of enterprises not applying at least some phase of the activities in the PLAN phase of energy management. The average implementation of the PLAN phase in the research sample is $32.56 \%$, which means that energy management planning is being implemented, but still not present sufficiently. From the histogram in Figure 1, it can be concluded that $46.15 \%$ of the enterprises have a level of application of requirements for the energy management system in the PLAN phase below average, while the percentage of organizations above average is $53.85 \%$. It can be concluded that most of the organizations in the sample are above the average application of the PLAN phase requirements for the energy management system. The full implementation of the requirements for the energy management system was found in $2.7 \%$ of the organizations in the sample, while only one organization in the survey reported the complete inapplicability of the requirements for energy management.

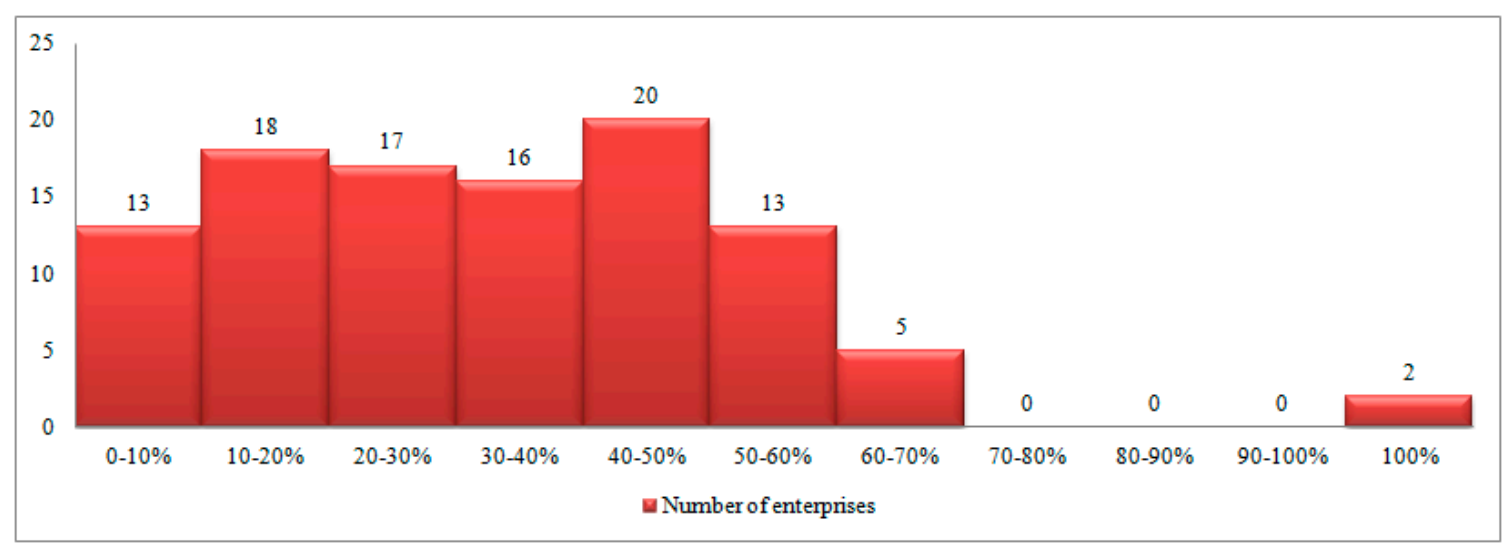

Figure 1. Application of the PLAN phase in enterprises in the research sample.

\subsection{Implementation of the Energy Management System-The DO Phase of EnMS}

The second phase of the energy management model according to ISO 50001 is the DO phase, which represents the absolute inclusion of employees, communication within the enterprise, an energy-related documentation system, as well as a process approach to energy management. The entire documentation system can be divided into the one that can provide guidance on how to implement activities, and the other that confirms that an activity has been performed. For successful enterprises, both forms of reporting and communication are necessary. Also, without motivation and involvement of employees in energy management, there can be no significant improvement. First, it is necessary to inform and then motivate employees to take part in improving energy efficiency. $31.73 \%$ of the researched enterprises have the average level of applying the requirements that relate to the inclusion of employees according to the requirements of EnMS. If employees are not motivated and do not see the significance of it, they will not be able to achieve great improvements in the process itself, which will in turn result in possible savings. Therefore, employees need to be informed about the importance of energy performance and energy efficiency of processes and then motivated by the management to fully participate in the implementation of EnMS. Employee motivation should also be reflected in free communication and submission of proposals for energy efficiency.

The data related to whether employees in their annual/monthly/weekly reports include data related to energy consumption shows that $48.56 \%$ of the enterprises in the sample responded positively. Also, $23.56 \%$ of the researched enterprises motivate employees to have activities in which they monitor, measure, document, or report on energy consumption at any level. The data regarding employees training shows that only $24.52 \%$ of respondents provide employees the opportunity to attend or complete any training, course, or lecture related to effective energy use and energy management. Employee training is very important, both for enterprises and their readiness for the management 
system implementation, as well as for monitoring actual trends and news in that field. About one third of the enterprises, or more precisely $30.29 \%$, indicated their readiness to organize training and/or employee meetings regarding education on energy management and its significance. Here the lack of leadership can be noticed in terms of promoting the significance of energy performance of processes and enterprises in general.

Communication related to energy management enables managers and employees to be informed about all problems related to energy consumption, saving measures, and process improvements. In order to achieve energy goals in advance, through defined action plans, it is essential that employees freely communicate on all relevant data. The researched enterprises gave a very satisfactory response in this part of research. Namely, the average level of application of the requirements concerning communication within the enterprise in terms of energy management is $54.65 \%$. According to the respondents, it can be concluded that there is free communication in enterprises and that the management encourages an exchange of information on energy management. The share of $36.54 \%$ of the researched enterprises exchange information related to energy consumption or energy use (in meetings, mail transcripts, etc.). It is significant that $63.94 \%$ of enterprises encourage free communication related to energy savings, and that $63.46 \%$ of the surveyed enterprises encourage employees to make suggestions and comments related to improving energy efficiency of individual processes. Very often, the management exchanges its own experience of energy management with other enterprises of a similar profile (through its associations, clusters, various fairs, etc.) and thus come up with ideas for possible energy savings and improvement opportunities.

EnMS documentation points out the existence of procedures and rules for document management and is related to energy consumption, energy savings, and improvement proposals. Generally speaking, the documentation system in an enterprise can be divided into documents that indicate the execution of a certain activity, as well as the manner of execution, and documents that indicate performed activities, results, and measures for improvement. In addition to the existence of certain documentation, it is very important to prescribe the appropriate procedures for document management, archiving, reporting, traceability, and priority. In this part of the research, the average level of requirement applications was $25 \%$. Enterprises do not use enough written reports, procedures, etc. related to energy management. Regarding individual answers, $23.56 \%$ of enterprises stated that they had some sort of documentation related to energy management, referring to all procedures, plans, reports, activities, instructions, etc. Additionally, $26.44 \%$ of enterprises have clearly defined procedures for managing documentation related to energy management. For most enterprises, the documentation related to energy management is part of the documentation related to the environmental management system, as well as the quality management system. The existence of documentation management procedures mainly relates to methods of issuing, authentication, archiving, or modification of documentation, which relate to energy management, but enterprises do not possess any software that would manage this documentation system in any way.

In order to properly monitor the operational processes within an enterprise and enable adequate management, it is necessary to identify all processes, with all sub-processes, activities, necessary resources, and engaged personnel. All processes in an enterprise convert the input (raw material, information) into the output (product or/and service that is further allocated to the buyer). Regarding energy management, in addition to identifying and adequately describing and defining business processes, it is also necessary to identify the energy flows in all processes, as well as those processes that have enviable or inadequate energy performance and thus significantly influence the energy efficiency of the process and the enterprise as well. The average level of application requirements within the process approach is $52.4 \%$ for the researched enterprises. Regarding the process approach to energy management, $56.25 \%$ of enterprises know and can identify processes that significantly influence energy consumption. This data is very important because it shows that the management in these enterprises is aware of energy consumption and energy performance in certain processes or parts of the process. It also indicates the readiness of the enterprise for optimum energy consumption, because 
the identification of significant consumers can lead to certain measures that are necessary to achieve the desired energy efficiency. This is indicated by the fact that $63.46 \%$ of the researched enterprises can identify processes where it is possible to increase energy efficiency. In order for machines, devices, units to work properly and without any losses in the production process, it is necessary to comply with all instructions for use, maintenance, and servicing. In this regard, 37.5\% of the researched enterprises have clearly defined procedures related to the operation and maintenance of machines, tools, and equipment, especially in significant processes, i.e., in processes that significantly contribute to energy consumption and energy use.

Figure 2 shows the application of the DO phase in enterprises in Serbia. Full implementation of the activities of the management system in the DO phase is not present in any researched enterprises. The average implementation of the DO phase is $41.51 \%$, indicating that the implementation of the energy management definitely has potential for improvement. It can be observed that $36.54 \%$ of enterprises have a level of application of requirements for the energy management system in the DO phase below average, while the percentage of enterprises above average is $63.46 \%$.

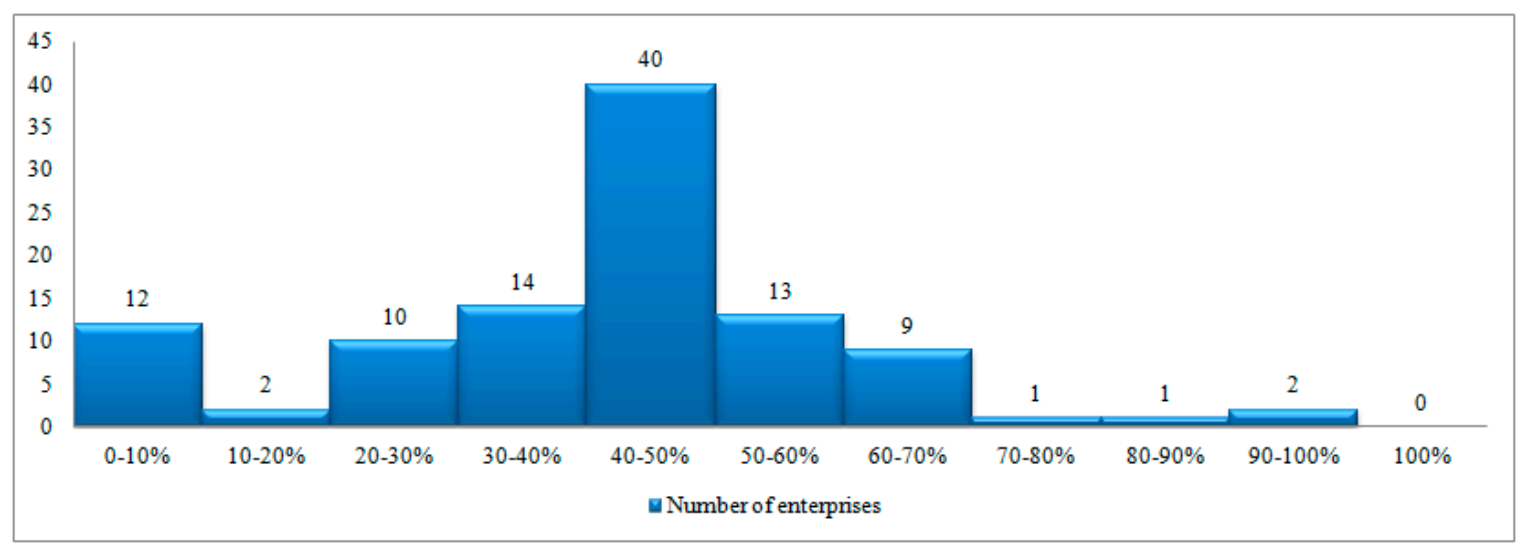

Figure 2. Application of the DO phase in enterprises in the research sample.

\subsection{Monitor, Measure and Analyze Business Processes-The CHECK Phase of EnMS}

Factual based decision-making is an integral phase of the CHECK phase of the EnMS model according to ISO 50001. Also, factual based decision-making is one of the eight principles of quality management. For an enterprise's management to make a decision based on facts, there should be a developed system of data collection and processing, so that they can be available for comparison, analysis and forecasting. The availability of data allows predicting and proactively responding to problems, as opposed to reactive actions when or after a problem occurs. The researched enterprises responded very positively in this part, namely, the average level of application that relates to factual based decision-making was $39.72 \%$. The obtained data indicate the need for energy managers to educate themselves in the implementation of techniques and tools for collecting, processing data, and making trends and forecasting analysis, which would be easy to use for the enterprise's management, on the basis of which they should make important business decisions, plan certain activities, and include them in the enterprise's strategic plan.

Here, it is quite significant that $58.68 \%$ of the researched enterprises know and can define the largest consumers within their enterprise. This refers to a particular plant, part of the plant, equipment, system, process, part of a process, or a significant sub-process. However, not so encouraging is the fact that only $15.38 \%$ of the researched enterprises determine the current energy performance of the plant, installed equipment, system, or processes, in order to identify significant energy consumers. As far as cost prediction is concerned, $47.12 \%$ of the researched enterprises can estimate energy consumption, as well as expected costs in the future, based on their current costs, consumption, and predetermined plans and targets. In $35.58 \%$ of enterprises, a list of priorities related to possibilities for improving 
the energy performance can be identified and is being made. Additionally, $52.4 \%$ of the researched enterprises follow the development of new devices, systems, and production lines that have better energy performance. In $39.9 \%$ of the researched sample, there is a person within the enterprise that deals with monitoring, recording, and reporting on energy consumption and system savings in a certain way. In $37.98 \%$ of enterprises, there is a record of all significant accidents or deviations related to the variation in the expected energy consumption. Additionally, only $30.77 \%$ of enterprises possess evidence of how much energy is spent on the production of one product from the assortment. This data refers to the cost of a product or service through the use of energy.

Figure 3 shows the implementation of the CHECK phase in enterprises in Serbia. Full monitoring of the functioning and effecting of the energy management system is present in only $1.92 \%$ of enterprises, and very low implementation is present in even $22.12 \%$ of enterprises. The implementation of the CHECK phase is $39.72 \%$, which shows that controlling and monitoring the energy management process is certainly not on the significant level. From the histogram (Figure 3) it can be observed that $48.08 \%$ enterprises have a level of application of requirements for the energy management system in the CHECK phase below average, while the percentage of enterprises above average is $51.92 \%$. It can be said that more than half of the enterprises are above the average application of requirements of the verification phase, the monitoring or the functioning of EnMS.

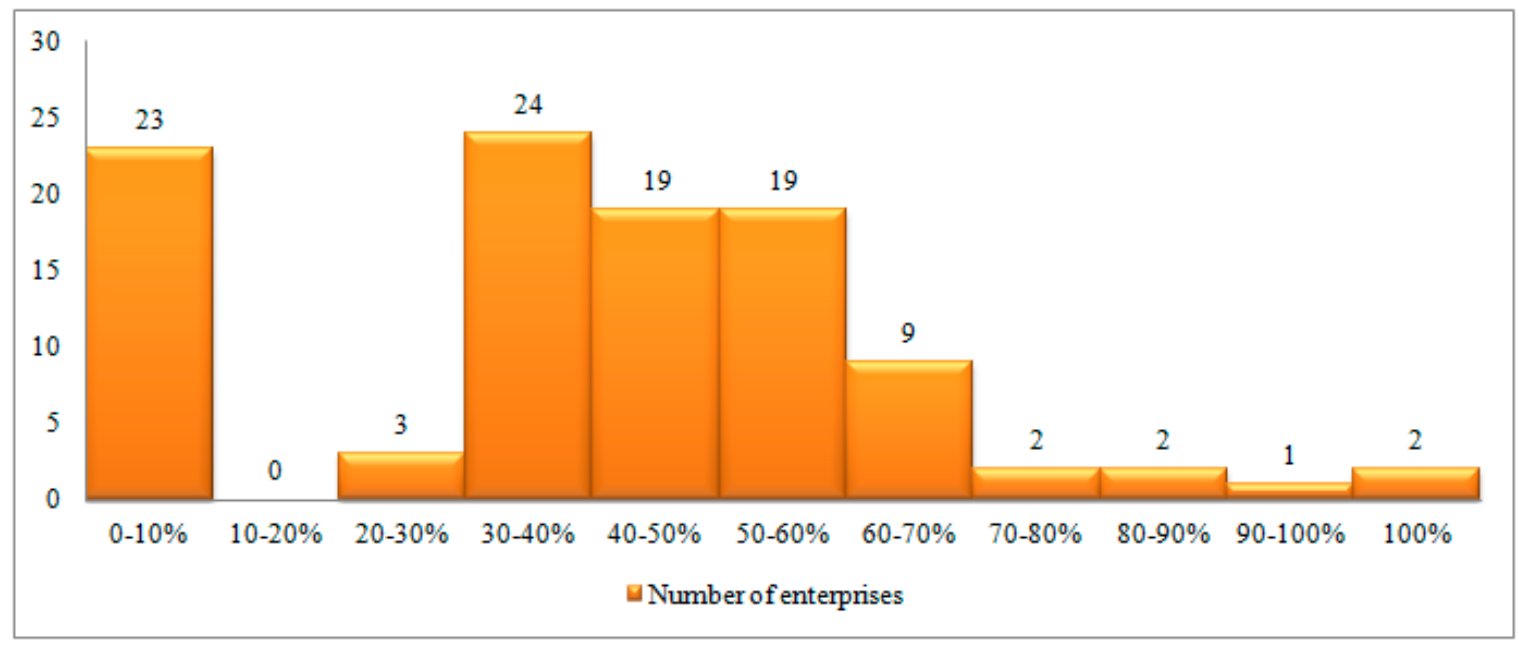

Figure 3. Application of the CHECK phase in enterprises in the research sample.

\subsection{Management Review and Continual Improvements-The ACT Phase of EnMS}

Reviews and continuous improvements are the basis of the ACT phase of the energy management model according to the ISO 50001 standard. Internal audits and reviews of EnMS conducted by the management represent the opportunities to determine the current state regarding the energy performance of the enterprise and its energy management system, as well as to consider possible ways of improvement. The average level of application within this requirement of energy management is $15.25 \%$. The research results show that $30.29 \%$ of enterprises conducted management reviews of energy management (spending, saving, increasing energy efficiency), while $25.48 \%$ of enterprises defined corrective actions and/or plans related to the current problem of energy consumption at the quarterly and/or annual level. As for preventive measures, actions and/or plans related to energy management, only $11.54 \%$ of enterprises recognized their definitions as very important and implemented them in a certain period. However, $12.02 \%$ of the researched enterprises considered that the opinion of their consumers/users of their services was not formed based on the rational energy use within their enterprise, which is an unrepresented fact for raising the awareness of customers or service users. Additionally, $5.29 \%$ of enterprises considered that energy savings in process activities are in direct relation to the satisfaction of consumers' expectation. The enterprises in the researched sample stated 
that they are largely not engaged by independent auditors for energy management audits, only $5.77 \%$ employ external energy audit experts. Finally, $16.35 \%$ of enterprises stated that their management defines the plans for the next period of actions, which will improve the process of production/provision of services in terms of energy management.

Figure 4 shows the ACT phase in the enterprises in Serbia. A complete review and improvement of the energy management system is not present in any enterprise in the sample, while very low implementation of this phase is present in no fewer than $41.35 \%$ of enterprises. The average application of the ACT phase is $15.25 \%$, indicating that the review and improvement of the energy management system is insufficiently present in the enterprises in the research sample and that it is necessary to concentrate further reviews at this stage. Regarding the distribution of the enterprises in the research sample, the level of application of requirements for energy management system in the ACT phase is below average in $75.00 \%$ of the given sample, while the percentage of organizations above average is only $25.00 \%$. A situation is quite different from the other stages of the application of the requirements of the management system. At this stage, additional efforts are needed to bring enterprises closer to the requirement of reviewing and improving energy management systems, thus completing the PDCA cycle.

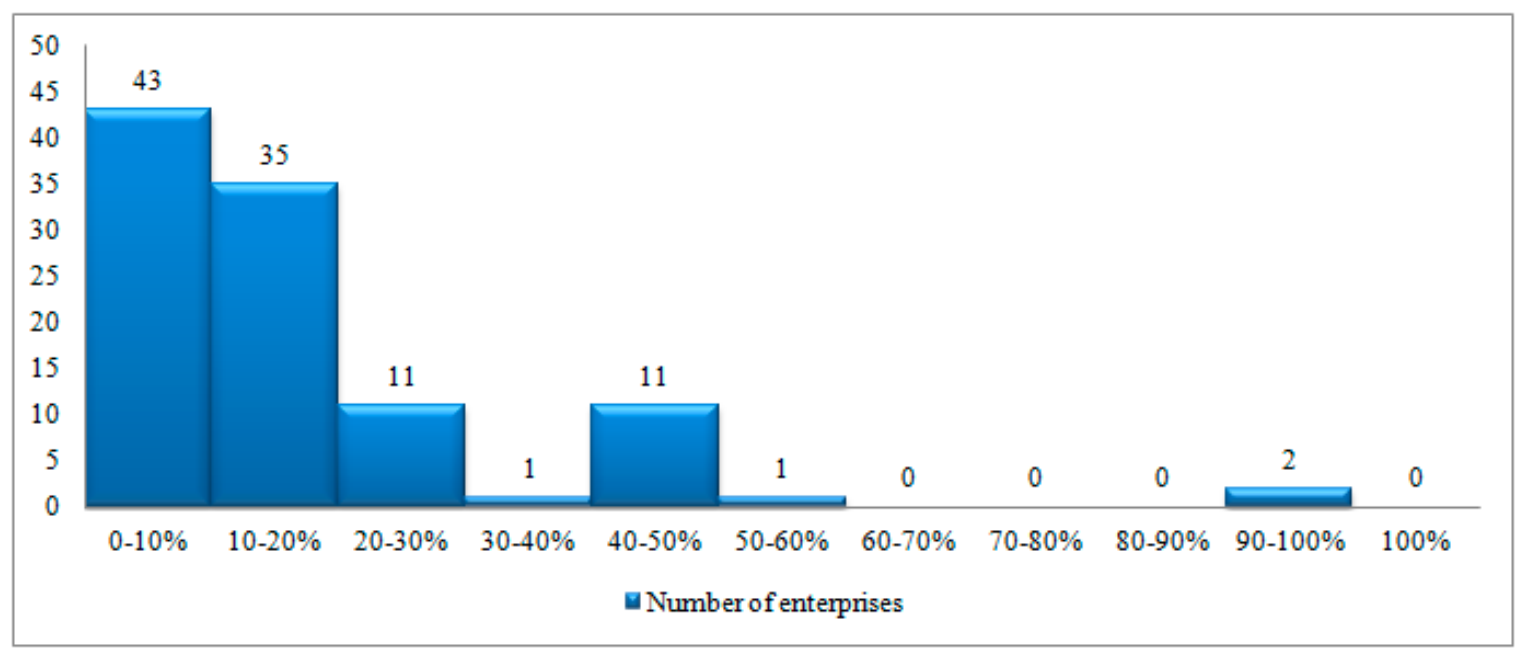

Figure 4. Application of the ACT phase in enterprises in the research sample.

\subsection{Analysis of Correlation between Enterprise Properties and EnMS}

It is of great importance to analyze and determine the impact of characteristics of enterprises and the level of requirement implementation of EnMs. Supplementary Figures S1 and S2 provide graphic representations of the EnMs implementation level for each enterprise and type of management system that enterprises have implemented and certified. Therefore, this data is taken into account for further analysis. The Mann-Whitney U test is used for this analysis.

First of all, the implementation of a certified quality management system is analyzed along with the data regarding the level of implementation of EnMS. The results of the analysis show that there is a significant difference in the level of energy management system implementation and whether the enterprises have certified quality management system or not. The level of energy management system implementation in enterprises that have a certified quality management system (median $M_{d}=36 \%$, $\mathrm{n}=57$ ) is significantly higher than in the ones that do not have one (median $M_{d}=18 \%, n=47$ ). The $\mathrm{z}$-score is 6.67841. The $p$-value is $p=0.00001$.

Also, the Mann-Whitney $U$ test has shown that there is a difference in the level of requirements implementation for EnMS between the enterprises that have a certified environmental management system (ISO 14001) (median $\mathrm{M}_{\mathrm{d}}=40.31 \%, \mathrm{n}=32$ ) and the enterprises that are not certified (median $\mathrm{M}_{\mathrm{d}}=26.02 \%, \mathrm{n}=72$ ). The $\mathrm{z}$-score is -6.53234 . The $p$-value is $p=0.00014$. 
In enterprises that have certified both a quality management system and an environmental management system, a higher level of energy management system requirements implementation is evident. The level of impact is even higher when it comes to the quality management system than for the environmental management system. Similar results were also shown in [31].

One of the enterprise properties that has a possible influence on EnMS requirements implementation is certainly the size of the enterprise. The Kruskal-Wallis test has shown that the level of requirements implementation for EnMS is higher in large enterprises (median $\mathrm{M}_{\mathrm{d}}=77.04 \%$, $\mathrm{n}=4$ ) than in the medium-sized enterprises (median $\mathrm{M}_{\mathrm{d}}=51.02 \%, \mathrm{n}=7$ ), or small enterprises (median $\mathrm{M}_{\mathrm{d}}=41.33 \%, \mathrm{n}=16$ ). The minimal level of EnMS application is present in micro enterprises (median $\left.\mathrm{M}_{\mathrm{d}}=27.55 \%, \mathrm{n}=77\right)$. Test value $\mathrm{X}^{2}=26.6263$ and $p$-value $p<0.00001$ show that the result is significant for $p<0.5$. The previous studies have shown that the enterprise size is important for the readiness and willingness for management system requirements implementation, as well as EnMS requirements implementation [23,31].

The territorial division by selected regions indicates not only the territorial affiliation, but also the development level of those regions and the predominant activities in those areas. All of this points to the possibility of varying enterprise development levels and, therefore, a different level of energy management requirements implementation. In this regard, the Kruskal-Wallis Test was used to analyze the impact of enterprise affiliation by region on the energy management implementation. The test results indicate that there is no significant difference in the territorial affiliation of the organization in the sample. Test value $X^{2}=2.012$, significance level $p=0.4699$. For enterprises registered in the Vojvodina region (sample with median $M_{d}=41.33 \%, n=17$ ), in Belgrade (median $M_{d}=53 \%, n=31$ ), in Šumadija and West Serbia (median $\mathrm{M}_{\mathrm{d}}=67 \%, \mathrm{n}=30$ ), and in South and East Serbia (median $\mathrm{M}_{\mathrm{d}}$ $=55.5 \%, \mathrm{n}=26$ ). The test results indicate that the territorial affiliation of the enterprise does not determine, i.e., has no effect on the level of energy management application.

\section{Discussion}

Analysis of the research shows that the level of application of energy management in enterprises in the research sample, observing the international standard ISO 50001 requirements implementation, is in the range of 0 to 98 points, which is also the maximum number of points that enterprises could get, counting all question groups that are used in the survey. The average points scored by the enterprises in the sample were 32.78. The energy management system requirements implementation in the Serbian wood industry is present slightly more than a third of enterprises and can be considered that it is not on the satisfactory level. The average level of application, if the whole survey is taken into account, is $33.45 \%$. The enterprises in Serbia generally have a systematic approach to energy management, but it is on a low level. It points to the insufficient willingness of the management to implement this management system. However, energy planning is hardly even present in the strategic planning of enterprises that have participated in the research. The documented system, as well as the involvement of employees is almost non-existent, and therefore there is no energy policy that would clearly define the directions for the implementation and development of an energy management system, as well as the review of the system and the implementation of proposed improvements. In order to present the results on a scale of $0-100 \%$, the analysis uses data of the percentage for the energy management system requirements application, which is calculated on the basis of the points obtained. Therefore, the level of requirements application ranges from $0 \%$ to $100 \%$, while the mean value is $33.45 \%$.

From the histogram presented in Figure 5, it can be concluded that $42.31 \%$ of the enterprises have a level of requirements application for EnMS below 30\%, while the percentage of enterprises above $30 \%$ is $57.69 \%$. The full requirements implementation for the energy management system was not found in any enterprise in the sample, while $12.5 \%$ of the enterprises surveyed have noted the complete inapplicability of the energy management requirements. 


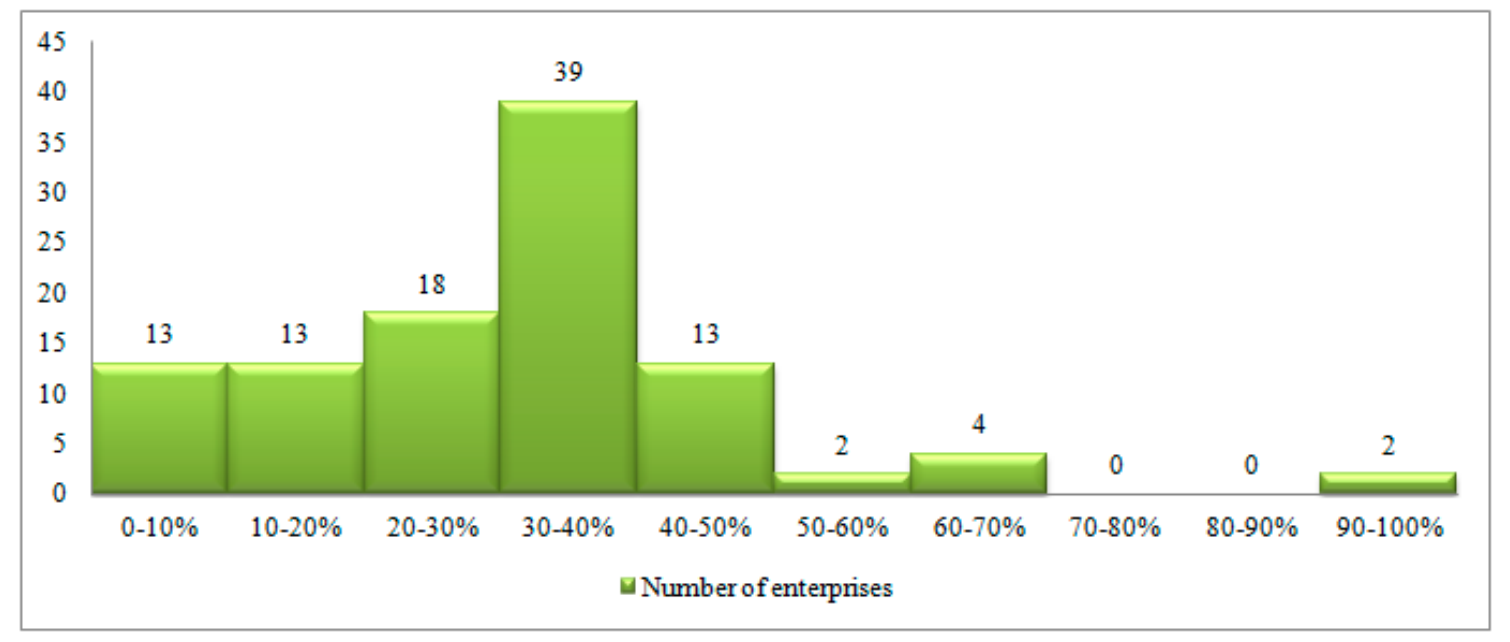

Figure 5. Implementation of energy management systems in enterprises in Serbia.

A similar, but not identical, study on the implementation of energy management measures was carried out in Denmark for the industry in general, stating that only 3-14\% of organizations implement energy management measures [32]. The level of implementation in Sweden was determined at 25-40\% [33], while in Turkey, the level of implementation of energy management measures was 22\% [34]. Research done in Italy indicates that $35 \%$ of organizations were ISO 50001 certified [35]. Based on the data pertaining to organizations in Serbia, a similar survey was conducted in [31], where the results indicate that the percentage of organizations implementing energy management measures is about $23 \%$. Similar, but not as extensive, research was conducted in Spanish organizations [36], where only eight organizations were interviewed, and in Portugal [37]. In the present study, the same model was not used as in the mentioned research papers for energy management requirements application, so that the obtained data can only be compared descriptively and approximately. The model that was used in the research was based on the Plan-Do-Check-Act model given in the standard and it included energy performance indicators analyzed and developed for a detailed study of enterprises, also including SMEs.

\section{Conclusions}

Based on the presented results, it can be said that the average enterprise in Serbia in the wood industry, in terms of the energy management system, can be described as follows: The system approach is under-implemented; top management is not sufficiently committed to energy management and takes the measures that its finances allow; energy policy is generally not defined; energy use is planned sporadically; employees are not involved in energy management; communication on energy management is not frequent and on a regular basis; documentation system is not at an enviable level; energy indicators serve to monitor the achievement of energy goals; the data collected through monitoring and measurement are analyzed; data and trends are reviewed, but often not applied, as there is often no financial basis for implementing the improvements provided by the data from the analysis.

Based on the collected and processed data, it can be concluded that enterprises in Serbia that have implemented and certified the Quality management system (ISO 9001), Environmental management system (ISO 14001) and Occupational health and safety assessment series (OHSAS 18001) simultaneously, have an average level of application of energy management requirements over $36 \%$. About $45.19 \%$ of enterprises do not have any management system implemented and certified, even though their average level of application of energy management requirements ranges from $0.0 \%$ to $44.9 \%$. It was shown that enterprises that have a certified quality management system (ISO 9001) have a higher level of energy management system implementation, as well as that large and 
medium-sized enterprises have a more significant EnMS requirements implementation than small and micro enterprises.

Reducing costs and increasing profits, and therefore reducing energy use, represents the priority for every enterprise. As the ISO 50001 standard was revised and harmonized last year, the standard in Serbia is expected to be harmonized and revised in line with the current standard. It is also expected that in the forthcoming period, a package of laws and procedures regarding greenhouse gas emissions will be adopted in Serbia.

The presented research is planned to be conducted in other neighboring countries and the wood industry market as well, with the aid of the strong enterprise network. The results of such a comprehensive study will provide more precise and reliable results for policy makers.

The strength of this research is the approach for identifying the level of implementation of EnMs, the classification algorithm by using analytical tools, and that it can be easily implemented in different industrial environments, conditions, and legal limitations. The weakness can be observed in the competence of the personnel that is interviewed in the study. It should be managerial positions or energy managers that have basic knowledge of necessity of energy preserving. The limitation can be identified in insufficient cooperation with companies and their willingness to participate in the study. The workers in such companies should be aware of the implementation of energy saving measures in all processes, and without their willingness, this cannot be achieved at any level. The future work will include other important sectors as well as the proposal of a model for motivating employees to improve their energy management knowledge and examining the factors that influence employees' motivation for energy management.

Supplementary Materials: The following are available online at http://www.mdpi.com/2071-1050/12/1/76/s1, Supplementary Figures S1 and S2, Tables S1 and S2.

Author Contributions: Conceptualization, M.N.R. and R.M.M.; methodology, M.N.R. and R.M.M.; software, M.N.R.; validation, P.M. and R.M.M.; formal analysis, M.N.R.; investigation, M.N.R.; resources, R.M.M. and P.M.; data curation, D.P.; writing—original draft preparation, M.N.R.; writing—review and editing, R.M.M. and P.M.; visualization, M.N.R.; supervision, R.M.M. and P.M. All authors have read and agreed to the published version of the manuscript.

Funding: This research received no external funding.

Acknowledgments: This paper presents the results of the research conducted within the project "Research and development of new generation machine systems in the function of the technological development of Serbia" funded by the Faculty of Mechanical Engineering, University of Niš, Serbia.

Conflicts of Interest: The authors declare no conflict of interest.

\section{References}

1. Min, H.; Galle, W.P. Green purchasing practices of US firms. Int. J. Oper. Prod. Manag. 2001, 21, 1222-1238. [CrossRef]

2. Suárez-Perales, I.; Carces-Ayerbe, C.; Rivera-Torres, P.; Suárez-Galvez, C. Is strategic proactivity a driver of an environmental strategy? Effects of innovation and internationalization leadership. Sustainability 2017, 9, 1870. [CrossRef]

3. Thiede, S.; Posselt, G.; Herrmann, C. SME appropriate concept for continuously improving the energy and resource efficiency in manufacturing companies. CIRP J. Manuf. Sci. Technol. 2013, 6, 204-211. [CrossRef]

4. Petrovic, S.; Milosavljevic, P.; Lozanovic Sajic, J. Rapid Evaluation of Maintenance Process Using Statistical Process Control and Simulation. Int. J. Simul. Model. 2018, 17, 119-132. [CrossRef]

5. Suh, S. Theory of materials and energy flow analysis in ecology and economics. Ecol. Model. 2005, 189, 251-269. [CrossRef]

6. Doty, S.; Turner, W. Energy Management Handbook; The Fairmont Press: Lilburn, GA, USA, 2009.

7. Arango-Miranda, R.; Hausler, R.; Romero-López, R.; Glaus, M.; Ibarra-Zavaleta, S.P. An Overview of Energy and Exergy Analysis to the Industrial Sector, a Contribution to Sustainability. Sustainability 2018, 10, 153. [CrossRef] 
8. Gavrlovic, D. Statistical Yearbook-Statistical Office of the Republic of Serbia; Statistical Office of the Republic of Serbia: Belgrade, Serbia, 2019.

9. Wilson, J. Life-cycle inventory of particleboard in terms of resources, emissions, energy and carbon. Wood Fiber Sci. 2010, 42, 90-106.

10. Gustavsson, L.; Sathre, R. Energy and $\mathrm{CO}_{2}$ analysis of wood substitution in construction. Clim. Chang. 2011, 105, 129. [CrossRef]

11. Sathre, R. Life-Cycle Energy and Carbon Implications of Wood-Based Materials and Construction. Ph.D. Thesis, Ecotechnology and Environmental Sciences, Mid Sweden University, Östersund, Sweden, 2007.

12. Puettmann, M.E.; Wilson, J.B. Life-cycle analysis of wood products: Cradle-to-gate LCI of residential wood building materials. Wood Fiber Sci. 2005, 37, 18-29.

13. Milovanovic, M.; Antic, D.; Rajic, M.; Milosavljevic, P.; Pavlovic, A.; Fragassa, C. Wood resource management using an endocrine NARX neural network. Eur. J. Wood Wood Prod. 2017, 76, 687-697. [CrossRef]

14. Korol, J.; Kruczek, M.; Pichlak, M. Material and energy flow analysis (MEFA)—First step in eco-innovation approach to assessment of steel production. Metalurgija 2016, 55, 818-820.

15. Fischer-Kowalski, M. Society's Metabolism-The Intellectual History of Material Flow Analysis, Part I, 1860-1970. J. Ind. Ecol. 1998, 2, 61-78. [CrossRef]

16. Fischer-Kowalski, M.; Hüttler, W. Society's Metabolism-The Intellectual History of Material Flow Analysis, Part II, 1970-1998. J. Ind. Ecol. 1999, 2, 107-136. [CrossRef]

17. Saidur, R.; Atabani, A.E.; Mekhilef, S. A review on electrical and thermal energy for industries. Renew. Sustain. Energy Rev. 2011, 15, 2073-2086. [CrossRef]

18. Mizuta, Y. A case study on energy saving and new energy services in Japan. Manag. Environ. Qual. Int. J. 2003, 14, 214-220. [CrossRef]

19. Pardo Martínez, C.I. Energy use and energy efficiency development in the German and Colombian textile industries. Energy Sustain. Dev. 2010, 14, 94-103. [CrossRef]

20. Neelis, M.; Patel, M.; Blok, K.; Haije, W.; Bach, P. Approximation of theoretical energy-saving potentials for the petrochemical industry using energy balances for 68 key processes. Energy 2007, 32, 1104-1123. [CrossRef]

21. Madlool, N.A.; Saidur, R.; Rahim, N.A.; Kamalisarvestani, M. An overview of energy savings measures for cement industries. Renew. Sustain. Energy Rev. 2013, 19, 18-29. [CrossRef]

22. Siitonen, S.; Tuomaala, M.; Ahtila, P. Variables affecting energy efficiency and $\mathrm{CO}_{2}$ emissions in the steel industry. Energy Policy 2010, 38, 2477-2485. [CrossRef]

23. Backlund, S.; Thollander, P.; Palm, J.; Ottosson, M. Extending the energy efficiency gap. Energy Policy 2012, 51, 392-396. [CrossRef]

24. Introna, V.; Cesarotti, V.; Benedetti, M.; Biagiotti, S.; Rotunno, R. Energy management maturity model: An organizational tool to foster the continuous reduction of energy consumption in companies. Int. J. Clean. Prod. 2014, 83, 108-117. [CrossRef]

25. Capehart, B.L.; Turner, W.C.; Kennedy, W.J. Guide to Energy Management; The Fairmont Press, Inc: Lilburn, GA, USA, 2006.

26. Petrecca, G. Industrial Energy Management: Principles and Applications; Springer Science \& Business Media: New York, NY, USA, 2012.

27. Piper, J.E. Operations and Maintenance Manual for Energy Management; Taylor \& Francis Group: Boca Raton, FL, USA; Routledge: London, UK, 2016.

28. International Organization for Standardization (ISO). The 50001:2011 Standard; ISO: Geneva, Switzerland, 2011.

29. Statistical Office of the Republic of Serbia. Municipalities and Regions in the Republic of Serbia; Statistical Office of the Republic of Serbia: Belgrade, Serbia, 2012; ISSN 1450-9075.

30. CEN/CLC. Report on the CEN/CLC TR 16103:2010. Energy Management and Energy Efficiency-Glossary of Terms; CEN/CLC: Brussels, Belgium, 2010.

31. Jovanovic, B.; Filipovic, J.; Bakic, V. Energy management system implementation in Serbian manufacturing-Plan-Do-Check-Act cycle approach. J. Clean. Prod. 2017, 162, 1144-1156. [CrossRef]

32. Christoffersen, L.B.; Larsen, A.; Togeby, M. Empirical analysis of energy management in Danish industry. J. Clean. Prod. 2006, 14, 516-526. [CrossRef] 
33. Thollander, P.; Ottosson, M. Energy management practices in Swedish energy-intensive industries. J. Clean. Prod. 2010, 18, 1125-1133. [CrossRef]

34. Ates, S.A.; Durakbasa, N.M. Evaluation of corporate energy management practices of energy intensive industries in Turkey. Energy 2012, 45, 81-91. [CrossRef]

35. Bonacina, F.; Corsini, A.; De Propris, L.; Marchegiani, A.; Francesco, F.M. Industrial Energy Management Systems in Italy: State of the Art and Perspective. Energy Procedia 2015, 82, 562-569. [CrossRef]

36. Laskurain, I.; Ibarloza, A.; Larrea, A.; Allur, E. Contribution to energy management of the main standards for environmental management systems: The case of ISO 14001 and EMAS. Energies 2017, 10, 1758. [CrossRef]

37. Antunes, P.; Carreira, P.; Mira da Silva, M. Towards an energy management maturity model. Energy Policy 2014, 73, 803-814. [CrossRef]

(C) 2019 by the authors. Licensee MDPI, Basel, Switzerland. This article is an open access article distributed under the terms and conditions of the Creative Commons Attribution (CC BY) license (http://creativecommons.org/licenses/by/4.0/). 